\title{
Stock Analysis Based on Value Investment
}

\author{
Yuou Liu ${ }^{1, *}, \dagger$ Yu Shi ${ }^{2, \dagger}$ Yuke Shi $^{3, \dagger}$ \\ ${ }^{1}$ School of Management and Economics, Chinese University of Hongkong (Shenzhen), Shenzhen, Guangdong 518000, \\ China \\ ${ }^{2}$ School of Finance, Nanjing University of Science and Technology, Nanjing, Jiangsu 410000, China \\ ${ }^{3}$ School of Mathematics, University of California Irvine, Irvine, California, 92697, United of States. \\ ${ }^{*}$ Corresponding author. Email:118020289@link.cuhk.edu.cn9918107810116@njust.edu.cn \\ yukes1@uci.edu \\ These authors contributed equally.
}

\begin{abstract}
Nowadays, value investment has become an increasingly important measurement standard. This paper compares enterprises in three different industries to put forward various investment opinions more accurately. In this paper, the quantitative and qualitative research methods are mixed with studying and measuring the stock selection. The paper results are as follows: First, this paper selects stocks based on three factors: the P/E ratio, the EV/ EBITDA ratio, and the Profitability Yield. We recommend CNX MIDSTREAM PARTNERS LP as a good example of investment in horizontal and vertical comparisons with the analysis of these factors. Second, it is considered an important factor that CNX possesses natural environmental advantages and seizes the opportunity of the times in global warming. From the perspective of theoretical contribution, the research of this paper has a certain contribution to the theoretical development of value investment. From the practical point of view, this paper provides a reference for investors' actual investment decisions.
\end{abstract}

Keywords: case study, quantitative investment, SWOT analysis, value investment.

\section{INTRODUCTION}

Value investing is an investment strategy developed by Benjamin Graham and Dodd that focuses on searching and investing in undervalued stocks through fundamental analysis concepts [1]. Over the past years, value investors have achieved outstanding investment performance through analysis of stocks. Consequently, value investing has gradually become a hot topic in this century.

Since value investing has a long historic standing, many domestic and foreign scholars have done plenty of researches on value investment or utilizing value investment theory to conduct empirical research. Most of the domestic scholars focus on the efficiency of value investing in the Chinese market. Pan et al. found that Shanghai-Hong Kong Stock Connect Mechanism has brought Shanghai Stock Market's valuation back to rationality by not only introducing mature overseas investors but broadening the range of investment for domestic investors as well [2]. Similarly, research done by HUANG et al. shows that the more cumulative dividends a company shares, the higher market value it has, leading to the conclusion that Chinese investors appreciate value investment [3]. GAN et al. argues that although there is still speculation in China's capital market, value investments based on profitability and growth are still valid [4]. Fan Shuai has found that with the extension of the accounting period, the value correlation of accounting information shows an increasing trend. As a result, China's stock market has the function of value discovery in the long run, and investors can obtain satisfactory returns by fully exploring the corporate value based on accounting information [5]. Others have taken advantage of value investing to support their suggestions for investing strategy. A ranking mechanism based on the main skeleton of feature selection, feature evaluation, and complete ranking modeling is proposed by SONG et al. [6].

Some of the foreign scholars confirm the necessity and function of value investing through empirical researches. Piotroski found out that the information reflected in credit spreads has a significant lag in predicting default rates, indicating that value investing plays an important role [7]. Chhaya claims that "value strategies" are superior to the relative' relative' growth strategies and find the existence of value premium in the 
Indian stock market [8]. However, many approaches to value investing have suffered, which gives rise to various researches to explain the reasons. Israel et al. found significant evidence that basic information is related to the stock price, but in some periods, stock prices become less correlated with fundamental information [9]. Lev identify two major reasons for the failure of value investing: accounting deficiencies leading to inaccurate identification of value and the change of fundamental economic developments [10]. Kok et al. argues that the term "value investing" is increasingly being adopted by quantitative investment strategies that use ratios of common fundamental metrics to market price. These strategies are lacking strong evidence of their excellent performance and ignore identifying undervalued securities. In other words, they are confused with value strategies [11].

To sum up, since the controversial parts of value investing can mostly be explained by the definition and statistical misunderstanding, many scholars have proved the significance of value investing. However, most research on value investment focuses more on the macro analysis but has not yet reached substantive research on specific indicators. This paper will start with three specific companies measuring in multiple methods and combine value investment and SWOT analysis method to make a comprehensive investment analysis and recommendations targeted on shares of three companies.

\section{DATA AND METHOD}

\subsection{Data}

The data are stock data and financial data from three companies called OSHKOSH CORP, CNX MIDSTREAM PARTNERS LP, and DELTA AIRLINES INC from 2015 to 2019. The data includes earnings per share and stock prices of these three companies in the past five years. The source of all the data is Yahoo Finance.

\subsection{Method}

The research paper will analyze the development of those companies both quantitatively and qualitatively.

For quantitative analysis, the P/E ratio, EV/EBITDA ratio, profitability, and dividend yield will illustrate the company operating conditions. share

$\mathrm{P} / \mathrm{E}$ Ratio = market value per share $/$ earnings per

According to Investopedia audited by Jason Fernando [12], the $\mathrm{P} / \mathrm{E}$ ratio is a ratio for measuring the company's value. It is also called the price multiple or the earnings multiple. $\mathrm{P} / \mathrm{E}$ ratios are widely used to determine the relative value of a company's shares in an apples-toapples comparison by investors. Moreover, it can be used to make a comparison between the company itself and its historical record or between itself and other companies. The lower the P/E ratio is, the better the performance of the company is.

\section{EV/EBITDA}

$\mathrm{EV}=$ market value + total liabilities - total cash $=$ market value + net liabilities.

EBITDA $=$ EBIT + depreciation expenses + amortization expenses

EBIT $=$ operating profit + investment income + nonoperating income - non-operating expenses + net profit

EV means company value,

EBITDA means earnings before interest, tax, depreciation, and amortization

\section{EBIT means earnings before interest, tax}

EV/EBITDA, also known as enterprise value multiple, is a widely used company valuation index [13]. The value of the company can be calculated by the EV/EBITDA method. EV/EBITDA is the same as the relative valuation index, such as the price-earnings ratio $(\mathrm{P} / \mathrm{E}$ ratio). Its multiple is higher than the industry average or historical level, which usually means overvalued, while lower means undervalued. Different industries or sectors have different valuation (multiple) levels.

Dividend yield $=$ annual dividends per share/price per share

The dividend yield is a financial ratio showing the amount of a company's payout in dividends per year relevant to its stock price [14]. The amount of money offered by the company that shareholders invest in for possessing a share of stock is divided by its current stock price. Mature companies may pay dividends. However, a higher dividend yield does not equal guaranteed attractive investment opportunities. The dividend yield of a stock may be high because of the decline of its stock price.

For qualitative analysis, SWOT analysis is widely employed to demonstrate the development of the company.

SWOT represents strengths, weaknesses, opportunities, and threats, which is a useful criterion to assess business [15].

In general, SWOT analysis can be separated into two parts [16]. Using various investigation and research methods, it can analyze various environmental factors in which the company is located, namely external 
environmental factors and internal capability factors. The external environment factors include opportunity factors and threat factors, which are favorable and unfavorable factors that directly impact the company's development and belong to objective factors. The internal environmental factors include strengths and weaknesses, which are positive and negative factors in the company's own development and are subjective. When investigating and analyzing these factors, history, present situation, and future development should all be considered.

Strengths are the internal factors of an organization, including favorable competitive situation, adequate financial resources, good corporate image, technical strength, economies of scale, product quality, market share, cost advantage, advertising campaigns, etc.

Weaknesses are also internal factors of the organization, including equipment aging, management confusion, lack of key technologies, backward research and development, shortage of funds, poor management, product backlog, poor competitiveness.

Opportunity is an external factor of an organization, including new products, new markets, new demands, foreign market barriers are lifted, competitor mistakes, etc. Threats are also external factors of organizations, including new competitors, increased alternative products, market tightening, industry policy changes, economic recession, customer preference changes, emergencies, etc.

\subsection{Method and case selection}

The case study methodology is suitable for this research for three causes. First, this paper aims to illustrate why CNX MIDSTREAM PARTNERS LP is a good investment choice. The case study method is, therefore, a good way to show reasonability from various perspectives. Second, this research aims to systematically probe into the process mechanisms for value investing, and the demand for data richness is high. The frameworks of different companies used for value investing are complicated and multi-dimensional, making it much more appropriate to analyze the problem by examining organizational context instead of simply adopting a quantitative approach [17]. Third, academic research on value investing is still limited and at the exploratory stage. This research explores the various standard for value investing and analyzes those companies from both quantitative and qualitative approaches. The exploratory case study is particularly appropriate for all academic fields without sufficient adequate research [18].

Selecting CNX MIDSTREAM PARTNERS LP as the case study object is based on the following three criteria. First is the principle of importance and representativeness [8]. CNX MIDSTREAM PARTNERS LP is a growth-oriented major limited cooperative company, which owns the business development and acquisition of natural gas collection and other midstream energy assets. It is a leading enterprise in the energy field. It has set up a model in the industry. Therefore, choosing CNX MIDSTREAM PARTNERS LP as a case study company obeys the importance and representative principles of case selection. Second is the principle of theoretical sampling. The selection of the case study object is based on the requirement to fill in the existing theoretical gaps or develop new theories, rather than statistical sampling reasons [19]. Although previous studies considered the quantitative methods for value investment in CNX MIDSTREAM PARTNERS LP, there is still a lack of the combination of using qualitative and quantitative methods for value investing. This study uses quantitative statistics such as P/E Ratio, EV/EBITDA, dividend, and qualitative methods like SWOT analysis to better illustrate the development of CNX MIDSTREAM PARTNERS LP to fill the existing research gap. The third is the consistency between the company's theoretical goal and its practice. CNX MIDSTREAM PARTNERS LP aims to increase the market share and earn more profit. The actions taken to push the development of the company are in accord with the theoretical goal.

\section{RESULTS AND DISCUSSION}

This part uses quantitative and qualitative research methods to conduct an in-depth analysis of three stocks. Among them, quantitative research methods are used to determine the value of corporate assets, while qualitative research methods focus on evaluating corporate soft value. Both support the research conclusions of this article.

\subsection{Quantitative analysis of enterprise value: $P / E \& E V / E B I T D A$, Profitability, and Dividend Yield of CNX are better than the other two company}

There are three stocks for us to choose from stock: OSHKOSH CORP, CNX MINDSTREAM PARTNERS LP, and DELTA AIRLINES INC. To accurately analyze which stock is more worthy of our investment, we need to use data to get results intuitively. We will discuss three aspects which are $\mathrm{P} / \mathrm{E}$ ratio, EV/EBITDA ratio, Profitability, and Dividend Yield.

Firstly, considering the $\mathrm{P} / \mathrm{E}$ ratio, the lower the $\mathrm{P} / \mathrm{E}$ ratio is, the more worth investing in the stock. Among the three firms we need to compare, $\mathrm{CNX}$ has the lowest ratio, which is 6.75 . It is $38.86 \%$ lower than the OSHKOSH CORP and $18.75 \%$ lower than DELTA AIR LINES INC. Thus, from the aspect of theP/E ratio, CNX is the best stock for us to invest in.

Secondly, when we come to the EV/EBITDA ratio, we can see that CNX is 7.42, which is slightly higher than that of OSHKOSH CORP and DELTA. Although the 
lower EV/EBITDA, the more attractive the stock is, the ratio of CNX is less than 10, which can be commonly interpreted as healthy and above average by analysts and investors. Moreover, its number still stays in the bottom $50 \%$ of the firms of the comparison group (the firms that stay in the P/E 5-to-15 range and above $\$ 1$ billion in market capitalization). From this aspect, we can conclude that CNX is still a good stock worthy of our investment.

Thirdly, from the aspect of profitability and dividend yield. We can see that the profitability of CNX is $25.63 \%$. Although the profitability of CNX is a little bit lower than OSHKOSH, it still higher than the average profitability, which is $19.51 \%$, of the comparison group (firms stay in $\mathrm{P} / \mathrm{E}$ 5-15 and above 1 billion dollars in market capitalization). Also, the Profit margin is not the only criterion for judging whether a stock is worth investing in. A slightly lower value in a certain aspect cannot directly determine the quality of a stock. In addition, considering the aspect of dividend yield, the larger of dividend yield, the better the stock is. CNX has a huge advantage. The dividend yield of $\mathrm{CNX}$ is 6.5 times that of OSHKOSH and is 3.7 times that of DELTA AIR LINES. Therefore, combined with the analysis of the previous three parts, we will choose CNX MIDSTREAM PARTNERS LP as our best investment idea.

\subsection{Qualitative analysis of enterprise value: The SWOT analysis method shows that CNX is worth investing in}

$\mathrm{S}$ (Strengthen): CNX is one of the largest independent natural gas exploration, development, and production companies. Compared with artificial gas, natural gas has the same calorific value price as artificial gas. Moreover, natural gas is clean and clean, which can prolong the cooker's service life and help customers reduce the expenditure of maintenance costs. Natural gas is a clean gas with a stable supply. It can improve air quality, thus providing a new impetus for economic development in the region, driving economic prosperity, and improving the environment. Since the benefits of natural gas, more and more people will be willing to use natural gas instead of artificial gas. The use of natural gas has a really good and stable prospect. Moreover, the company's technology is advanced and mature, and the company has the advantage of resource possession. Thus, the stock of this natural gas company will also have the potential to be invested.

W(Weakness): The company has incomplete management systems and does not have a set of standardized and systematic management systems. It is reactive. With the emergence of new problems, operators formulate new measures without conducting in-depth research or as other companies adopt new management systems and imitate them. They seldom take into account the logical relationship between the new system and the original system and whether the new system adapts to the company's actual situation. The result is that the system of management is not strong and relatively backward. Moreover, undeveloped information acceptance is a problem for the company. CNX needs a strong information acceptance system to continuously improve the company.

$\mathrm{O}$ (Opportunity): Because the global warming problem is very serious now. Countries all over the world are beginning to pay attention to this problem. In fossil energy, coal and oil are relatively high in carbon content. Natural gas as an energy source can reduce the use of coal and oil, thus greatly improving the problem of environmental pollution. As clean energy, natural gas can reduce sulfur dioxide and dust emissions by nearly $100 \%$, reduce carbon dioxide emissions by $60 \%$ and nitrogen oxides by $50 \%$, and help to reduce acid rain formation, relieve the global greenhouse effect, and fundamentally improve the quality of the environment. This will be a great opportunity for the natural gas industry. In addition, the emergence of some external factors or new phenomena and the proposal of government policies will also bring new opportunities to the natural gas industry.

T(Threat): I think the biggest threat is the other companies in the gas industry. CNX needs to continuously improve its technology and develop a good and stable operation model. That would make investors trust CNX to keep buying shares.

\section{CONCLUSION}

Based on stock data and financial data of three companies called OSHKOSH CORP, CNX MIDSTREAM PARTNERS LP, and DELTA AIRLINES INC from 2015 to 2019, this paper studies the investment option with the method of value investment and SWOT analysis. The results demonstrate two things. Firstly, through quantitative analysis, the P/E ratio, EV/EBITDA ratio, Profitability, and Dividend Yield all show the advantages of CNX. This is because CNX has the lowest ratio, which is 6.75 , a relatively low EV/EBITDA ratio compared to the comparison group, the highest dividend yield possessing significant differences with the other two companies, and relatively high profitability. Secondly, considering SWOT analysis, as one of the largest independent natural gas exploration, development, and production companies, CNX has strength in advanced and mature technology. It also has an advantage over other energy companies for the clean natural gas with environmental protection effect. CNX faces a future of opportunity since the world pays more attention to environmental pollution like global warming. Although considering other competitive companies and their incomplete management systems, CNX has spaces to improve. It still serves as a good option to invest.

For other companies in the gas industry, according to the development track of CNX, two suggestions are put 
forward here: the transformation of enterprise raw materials and the improvement of the enterprise management system. The use prospect of natural gas is good and stable. Not only its calorific value is equal to that of artificial gas, but also it is clean. While prolonging the service life of cookware and reducing the maintenance cost of customers, it can improve the air quality and promote the local economic development. Therefore, other companies in the gas industry should transform raw materials, gradually abandon the use of artificial gas, and use natural gas to better operate enterprises. The management system of the company plays an important role in the development of the company. When improving the enterprise management system in the gas industry, the new measures cannot be adopted hastily before careful investigation and study. Let alone copying the new management system of other companies and ignoring whether it applies to the company's operation and whether it conflicts with the original system. Gas enterprises should base themselves on developing their enterprises, carefully analyze problems, and learn new enterprise management models to promote the improvement of the enterprise management system.

In this paper, we use quantitative and qualitative research methods to analyze which one of the three stocks is more worth investing in. We finally concluded that CNX is the most developed stock we can invest in. This paper provides readers with clear and unambiguous analysis and gives them some advice when they doubt how to invest. In addition, this paper gives a very clear explanation of the analytic methods that we used so that readers can better understand the analytic methods, and it is also convenient for them in the future.

\section{REFERENCES}

[1] Lakonishok Josef, Shleifer Andrei, Vishny Robert W. Contrarian Investment, Extrapolation and Risk[J].Journal of Finance, 1994, 49 (5):1541-1578

[2] Pan Huifeng, Liu Xitong, Zhou Xuanyu. Does the Opening up of the Capital Market Promote the Return of Value Investment? -Evidence from Shanghai-Hong Kong Stock Connect Program[J]. Financial Markets,2018(11):77-86.

[3] HUANG Jian-huan, PAN Li-qin,SONG Hai-tao. Cannot Chinese Investors Don'tDon't Pay Attention to Value Investment? [J]. Commercial Reasearch,2015(09):64-70.

[4] GAN Wei-ming, ZHANG Di-xin. An Empirical Study on Multi-Factor Pricing Model in Chinese Capital Market Based on Value Investment[J]. Economic Survey.,2018,35(04):136-140.
[5] Fan Shuai et al. Value Investing: The cumulative Effect of Value Revelance[J]. Accounting Research,2018(04):36-44.

[6] SONG Peng, LIANG Jiye, LI Changhong. Research on Robust Stock Value Investing Decision Making: An Research Framework[J]. Journal of Beijing Institute of Technology (Social Sciences Edition),2016,18(03):75-83.

[7] Piotroski J D. Value investing: The use of historical financial statement information to separate winners from losers[J]. Journal of Accounting Research, 2000: $1-41$.

[8] Chhaya G, Nigam P. Value investing with priceearnings ratio in India[J]. IUP Journal of Applied Finance, 2015, 21(2): 34.

[9] Israel R, Laursen K, Richardson S. Is (systematic) value investing dead?[J]. The Journal of Portfolio Management, 2020, 47(2): 38-62.

[10] Lev B, Srivastava A. Explaining the recent failure of value investing $[\mathrm{J}]$. NYU Stern School of Business, 2019:1-29.

[11] Kok U W, Ribando J, Sloan R. Facts about formulaic value investing[J]. Financial Analysts Journal, 2017, 73(2): 81-99.

[12]EV/EBITDA - Guide \& Examples of How to Calculate EV/EBITDA[EB/OL]. Corporate Finance Institute, 2021. (2021)[2021 -05 -06]. https://corporatefinanceinstit ute.com/resources/knowledge/valuation/ev-ebitda/.

[13] CONSLER J, LEPAK G, HAVRANEK S. Earnings per share versus cash flow per share as predictor of dividends per share[J]. Managerial Finance, 2011, 37(5): 482-488.

[14]MCMILLAN D, WOHAR M. A PANEL ANALYSIS OF THE STOCK RETURNDIVIDEND YIELD RELATION: PREDICTING RETURNS AND DIVIDEND GROWTH*[J]. The Manchester School, 2012, 81(3): 386-400.

[15]LEE J, LEE S, JUNG K. Balanced SWOT: Revisiting SWOT Analysis through Failure Management and Success Management[J]. SSRN Electronic Journal, 2020.

[16] Helms M M, Nixon J. Exploring SWOT analysiswhere are we now? A review of academic research from the last decade $[\mathrm{J}]$. Journal of strategy and management, 2010: 215-151.

[17] Hausman J A, Leonard G K. The competitive effects of a new product introduction: A case study[J]. The Journal of Industrial Economics, 2002, 50(3): 237 263. 
[18] Gerring J. The case study[M]//The Oxford Handbook of Political Science. 2011: 1134-1159.

[19] Johansson R. On case study methodology[J]. Open house international, 2007: 48-54. 